\title{
Very Long-term Self-renewal of Small Intestine, Colon, and Hair Follicles from Cycling Lgr5 ${ }^{\text {tve }}$ Stem Cells
}

\author{
N. BARKeR,$*$ J.H. van Es, ${ }^{*}$ V. JAKS,${ }^{\dagger}$ M. KASPER,${ }^{\dagger}$ H. SNIPPERT, ${ }^{*}$ R. TOFTGÅRD, ${ }^{\dagger}$ \\ AND H. CleVERS* \\ *Hubrecht Institute, Uppsalalaan 8, 3584CT Utrecht, The Netherlands; ${ }^{\dagger}$ Karolinska Institutet, Department of \\ Biosciences and Nutrition, Novum, SE-141 57, Huddinge, Sweden
}

\begin{abstract}
The intestinal epithelium and the hair follicle represent examples of rapidly self-renewing tissue in adult mammals. We have recently identified a novel stem cell gene $\operatorname{Lgr} 5$ expressed in multiple adult tissues. At the bottoms of crypts in small intestine and colon as well as in hair follicles, Lgr 5 marks cycling cells with stem cell properties (Barker et al. 2007; Jaks et al. 2008). Using an inducible Lgr5-Cre knockin allele in conjunction with the Rosa26-LacZ Cre reporter strain, long-term lineage-tracing experiments were performed in adult mice. The $\operatorname{Lgr} 5^{+\mathrm{ve}}$ crypt-based cell generated all epithelial lineages during a 14 month period, implying that it represents the stem cell of the small intestine and colon. Similarly, lineage tracing during a 14-month period revealed that $\operatorname{Lgr} 5^{+\mathrm{ve}}$ cells located in the bulge of the hair follicle sustained multiple rounds of hair growth. These observations support the counterintuitive notion that $L g r 5^{+\mathrm{ve}}$ cells are actively cycling, yet represent long-term stem cells of these adult, self-renewing tissues.
\end{abstract}

\section{LGR5 ${ }^{+}$STEM CELLS IN SMALL INTESTINE}

The self-renewing epithelium of the murine small intestine is organized into crypts and villi (Gregorieff and Clevers 2005). In the mouse, it turns over every 3-5 days. A massive rate of cell production occurs in the crypts and is balanced by apoptosis at the tips of the villi. The analysis of chimeric mice and of mutagen-induced somatic clones (Winton and Ponder 1990; Bjerknes and Cheng 1999) and the study of regeneration upon injury have allowed an operational definition of stem cell characteristics. Self-renewing stem cells cycle steadily to produce the rapidly proliferating transit-amplifying (TA) cells capable of differentiating toward all lineages. The estimated number of stem cells is between four and six per crypt (Bjerknes and Cheng 1999). Three differentiated cell types (enterocytes, goblet cells, and enteroendocrine cells) form from TA cells at the crypt-villus junction. These cells continue their migration in coherent bands along the crypt-villus axis. Each villus receives cells from multiple different crypts. The fourth major differentiated cell type, the Paneth cell, resides at the bottom of the crypt.

We have previously described the Wnt/Tcf4 target gene program in colorectal cancer cells. This program is physiologically expressed in intestinal crypts (van de Wetering et al. 2002; van der Flier et al. 2007). Because Wnt signals thus constitute the major driving force behind the biology of the crypt (Korinek et al. 1998), we hypothesized that some $W n t / T c f 4(T c f 7 l 2)$ target genes may be specifically expressed in the stem cells. Indeed, the Lgr5/Gpr 49 gene was expressed in a unique fashion at crypt bottoms. This Wnt target gene was expressed in the crypts, but not the villi, of mouse small intestine. In situ hybridization revealed expression in a limited number of cells located at all crypt bottoms as well as in adenomas in the small intestine of an $A P C^{\mathrm{min}}$ mouse. This expression pattern clearly differed from that obtained with other Wnt target genes.
More than 30 years ago, Leblond and Cheng (1974) noted the presence of cycling cells between the Paneth cells and coined the name "Crypt Base Columnar" (CBC) cells. Cheng and Bjerknes (Bjerknes and Cheng 1981; Barker et al. 2007) and Gordon and colleagues (Stappenbeck et al. 2003) have proposed that these cells may harbor stem cell activity. The Lgr5 gene appeared to mark these cycling CBC cells, interspersed between Paneth cells (Barker et al. 2007). The Lgr5 gene encodes an orphan G-protein-coupled receptor (GPCR), characterized by a large leucinerich extracellular domain (Hsu et al. 1998).

Heterozygous Lgr5-LacZ knockin mice allowed us to detail the expression of Lgr5. Before birth, a dynamic and broad expression pattern was observed (N. Barker et al., in prep.). Around birth, Lgr5 expression was extinguished in most tissues. Expression in adult mice was restricted to rare, scattered cells in the eye, brain, hair follicle, mammary gland, stomach, adrenal gland, and intestinal tract. Lgr 5-LacZ expression was observed in slender CBC cells at the bottom of small intestinal and colon crypts. CBC cells typically expressed the Ki67 cell cycle marker. Bromodeoxyuridine (BrdU) labeling allowed us to define the average cycling time of CBC cells to be on the order of 1 day (Barker et al. 2007).

To document the potential "stemness" of $L g r 5^{+\mathrm{ve}} \mathrm{CBC}$ cells, we generated another knockin allele. An enhanced green fluorescent protein-internal ribosomal entry site (EGFP-IRES)-CreERT2 cassette was integrated at the first ATG codon of the Lgr 5 gene (Fig. 1). GFP expression was specifically seen in CBC cells at crypt bottoms of the small intestine of these mice (Fig. 2, left panel). Typically, the $\mathrm{GFP}^{+} \mathrm{CBC}$ cells were relatively broad at their base and contained a flat, wedge-shaped nucleus. In our original experiments (Barker et al. 2007), we crossed the EGFPIRES-CreERT2 knockin allele with the Cre-activatable Rosa26-LacZ reporter (Fig. 1) (Soriano 1999) and followed these mice during a 2-month period. Injection of 


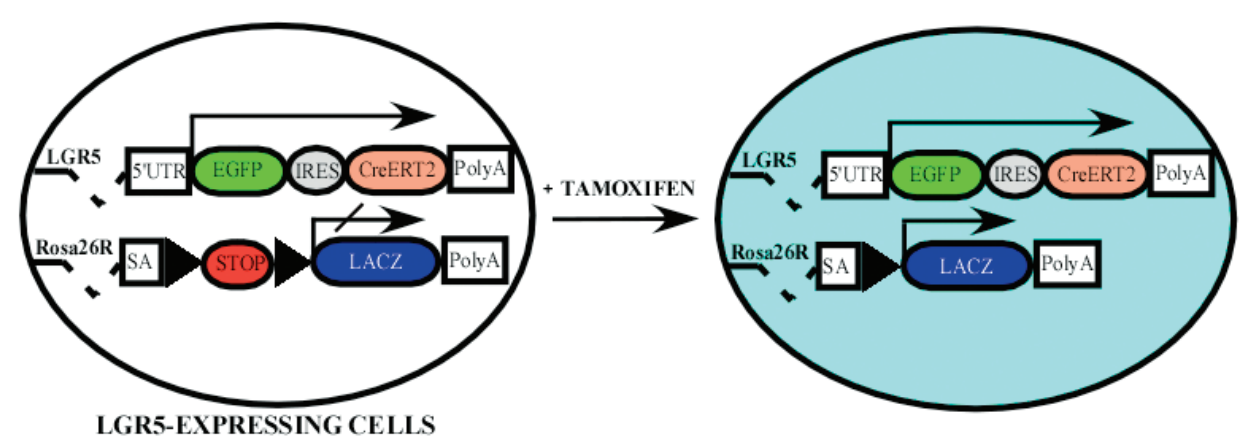

Figure 1. Expression of EGFP and CreERT2 from a single bicistronic message by gene knockin into the first exon of $\operatorname{Lgr} 5$. The resulting allele has been named EGFP-IRES-CreERT2 and was crossed with Rosa26-LacZ mice (Soriano 1999). Injection of tamoxifen activates the Cre fusion protein, resulting in activation of the $L a c Z$ reporter (right).

tamoxifen activates the CreERT2 fusion enzyme in Lgr5expressing cells. Cre-mediated excision of the roadblock sequence in the Rosa26-LacZ reporter should then irreversibly mark $\operatorname{Lgr} 5^{+\mathrm{ve}}$ cells. Moreover, although potential progeny of these cells will no longer express GFP, the activated $L a c Z$ reporter should act as a genetic mark, facilitating lineage tracing. $L a c Z$ expression was not observed in noninduced mice (not shown). When adult mice were subjected to a very low-dose tamoxifen pulse and were sacrificed at 1, 5, 12, 35, and 60 days postinduction, the following observations were made. One day postinduction, occasional CBC cells in the small intestine and colon expressed LacZ. Parallel ribbons of cells emanated from the crypt bottoms and ran up the side of adjacent villi at later time points. The numbers of these ribbons did not significantly change during a 2-month period (Barker et al. 2007). Importantly, double-labeling of 60-day-induced intestine revealed the presence of goblet cells, Paneth cells, and enteroendocrine cells in the LacZ-stained clones, underscoring the multipotency of the stem cells.

To determine whether the $\operatorname{Lgr} 5^{+\mathrm{ve}} \mathrm{CBC}$ cells constitute a stem cell pool that sustains self-renewal over the life span of a mouse, we decided to follow induced EGFPIRES-CreERT2 $\times$ Rosa26-LacZ mice for 14 months. LacZ staining of small intestines of these mice revealed that the numbers of clonal blue ribbons had remained essentially unchanged (Fig. 3). Histological analysis revealed thatlike the situation at earlier time points-all cell types of the epithelium were represented in the blue clones, corroborating the multipotency of the cells. These observations implied that the $\operatorname{Lgr} 5^{+\mathrm{ve}} \mathrm{CBC}$ cells represent long-term stem cells of the small intestine.

\section{$L G R 5^{+}$STEM CELLS IN THE COLON}

The colon epithelium contains crypts, but it has a flat surface rather than carrying villi. The epithelium comprises two major differentiated cell types: the absorptive colonocytes and the goblet cells (Gregorieff and Clevers 2005). Before the discovery of the Lgr5 marker, no stem cells had been identified in the colon. Analysis of the colon yielded essentially identical observations to what was seen in the small intestine. $\operatorname{Lgr} 5^{+\mathrm{ve}}$ cells with an appearance very similar to that of the CBC cells of the small intestine were observed in the EGFP-IRESCreERT2 mice (Fig. 2, middle panel) (Barker et al. 2007). When we crossed the EGFP-IRES-CreERT2 knockin allele with the Cre-activatable Rosa26-LacZ reporter (see
SI

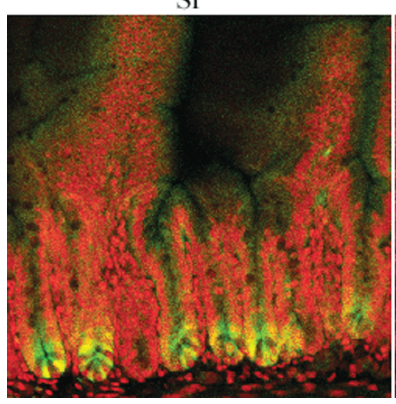

COLON

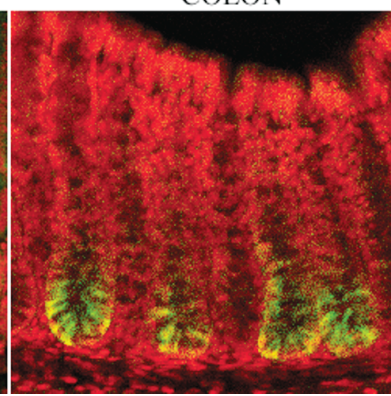

HAIR-FOLLICLES: SNOUT

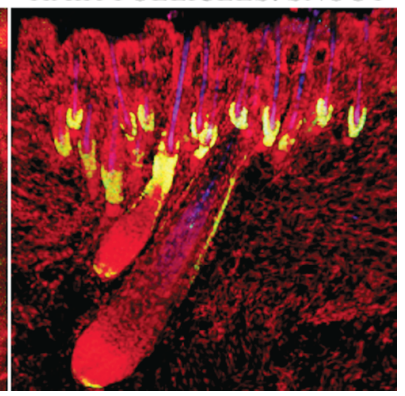

Figure 2. EGFP expression in an LGR5-EGFP-IRES-CreERT2 knockin mouse in the intestinal tract and hair follicle. Confocal GFP imaging was counterstained with the red DNA dye ToPro-3. (Left) Lgr 5 expression is restricted to the six to eight slender cells sandwiched between the Paneth cells at the crypt base of the small intestine. (Middle) Confocal imaging of EGFP expression in the colon confirms that $\operatorname{Lgr} 5$ expression is restricted to a few cells located at the crypt base. (Right) Confocal imaging of EGFP expression in the skin reveals Lgr 5 expression in the bulge and the secondary germ of the telogen hair follicle, as well as in the lower outer root sheath (ORS) of the anagen hair follicle. 


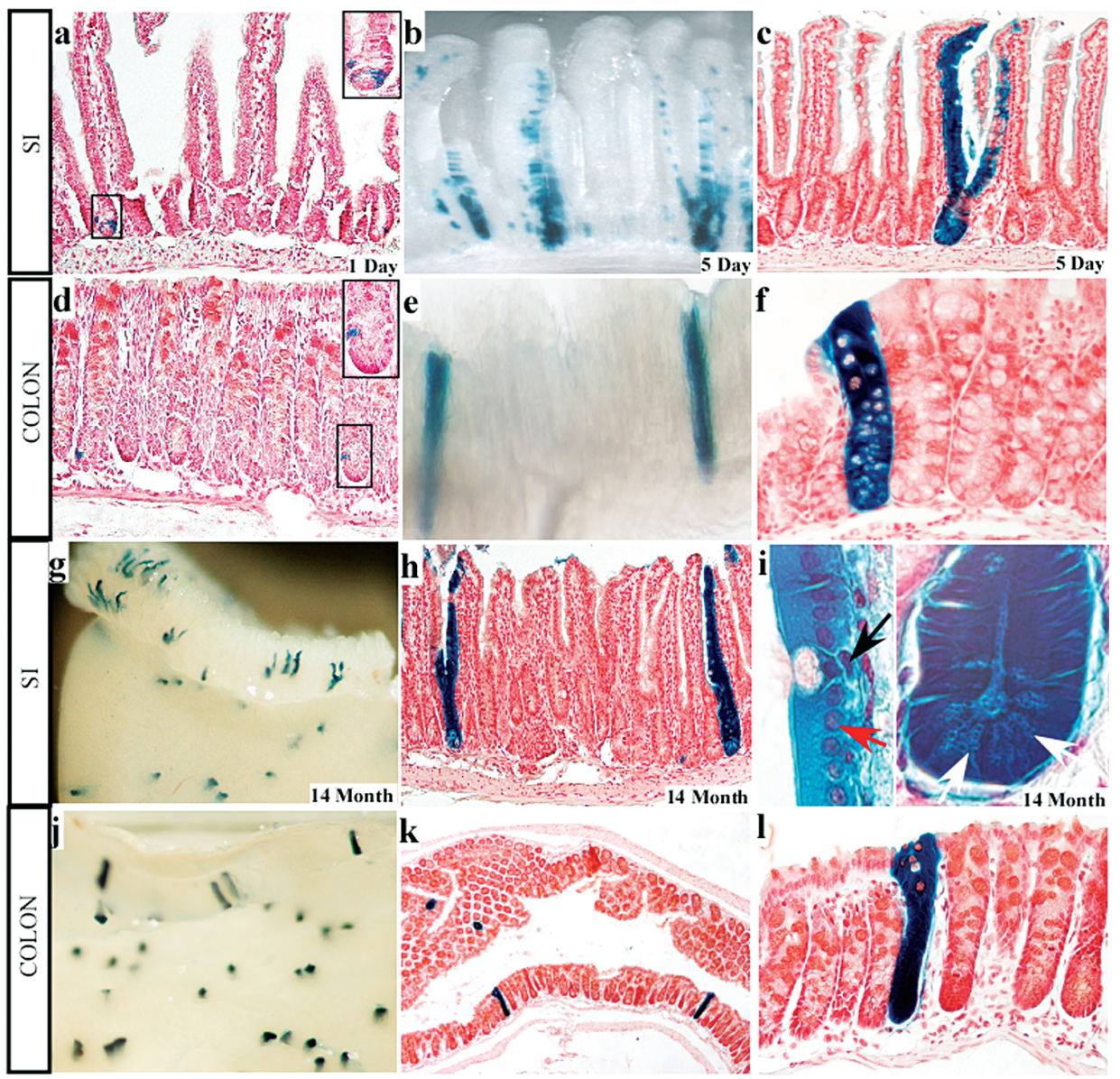

Figure 3. Very long-term lineage tracing in the small intestine and colon. (a) LGR5-EGFP-IRES-CreERT2 knockin mouse crossed with Rosa26-LacZ reporter mice 12 hours after tamoxifen injection; $(b)$ whole-mount analysis at day 5 postinduction; $(c)$ histological analysis of $b ;(d-f)$ same as $a-c$ for colon epithelium; $(g-i)$ whole-mount and histological analysis of tamoxifen-induced $L a c Z$ marking of small intestine after 14 months; $(j-l)$ whole-mount and histological analysis of tamoxifen-induced LacZ marking of colon after 14 months.

Fig. 1) and followed these mice during a 2-month period, the $\operatorname{Lrr} 5^{+\mathrm{ve}}$ cells yielded blue clones emanating from the bottoms of the colon crypts (Fig. 3) (Barker et al. 2007). These clones contained colonocytes as well as goblet cells and essentially remained unchanged during the 60 days of chase. One significant difference with the situation in the small intestine involved the kinetics of clone formation. At 5 days, blue staining in most crypts was still restricted to the bottom and entirely blue crypts were only rarely observed, implying that the colon stem cells were more often quiescent than their small intestinal counterparts.

To determine whether the $\operatorname{Lgr} 5^{+\mathrm{ve}}$ cells of the colon epithelium constitute a stem cell pool that sustains selfrenewal during the life span of a mouse, we analyzed the colon of induced EGFP-IRES-CreERT2 x Rosa26-LacZ mice after 14 months. $L a c Z$ staining revealed that the numbers of clonal blue ribbons had remained essentially unchanged (Fig. 3). Histological analysis revealed thatlike the situation at earlier time points - all cell types of the epithelium were represented in the blue clones, corroborating the multipotency of the cells. This is evidenced by the fact that no cells of labeled crypts were LacZ-neg- ative (Fig. 3f). These observations implied that the $\operatorname{Lgr} 5^{+\mathrm{ve}}$ cells represent long-term stem cells of the colon.

\section{LGR5 $5^{+}$STEM CELLS IN HAIR FOLLICLES}

The skin is the largest organ in mammals. The interfollicular epidermis (IFE) is a stratified, keratinized epithelium that is constantly self-renewing and essentially produces a single differentiated cell type, the keratinocyte. In contrast, the hair follicles undergo cycles consisting of growth, involution, and resting phases (Alonso and Fuchs 2006). The stem cells of the hair follicle are thought to reside in the hair follicle bulge and have been defined by expression of the CD34 cell surface marker, expression of cytokeratin 15 (Cotsarelis et al.1990; Trempus et al. 2003; Blanpain et al. 2004; Morris et al. 2004), and retention of either DNA or histone labels during long time periods (Braun et al. 2003; Tumbar et al. 2004). Cells with stem cell properties have been isolated from other areas of the hair follicles (Ito et al. 2004; Nijhof et al. 2006). Of particular interest, at certain stages of its cycle, the lower parts of the murine vibrissae follicle contain cells that can 
reconstitute a complete hair follicle upon transplantation (Oshima et al. 2001). Thus, the bulge might not be the only reservoir of stem cells. Indeed, studying $\operatorname{Lgr} 5^{+\mathrm{ve}}$ cells in the hair follicle, we have recently reported evidence for the notion that a $\operatorname{Lgr} 5^{+\mathrm{ve}}$ stem cell pool exists that can sustain hair follicles for up to 6 months (Jaks et al. 2008). Specifically, we found that an actively cycling $\operatorname{Lgr} 5^{+\mathrm{ve}}$ cell population exists in the bulge and the secondary germ of the telogen hair follicle, as well as in the lower outer root sheath (ORS) of the anagen hair follicle (see Fig. 2, right panel) (Jaks et al. 2008). Analysis of sorted cells in colonyforming and transplantation assays revealed that the Lgr $5^{+\mathrm{ve}}$ cells comprise an actively proliferating and multipotent stem cell population able to give rise to new hair follicles. We provided histological images of lineage tracing in induced EGFP-IRES-CreERT2 x Rosa26-LacZ mice to demonstrate that $L g r 5^{+}$cells maintained all cell lineages of the hair follicle during 6 months.

To determine whether the $\operatorname{Lgr} 5^{+\mathrm{ve}}$ cells of the hair follicles constitute a stem cell pool that sustains self-renewal during the life span of a mouse, we analyzed the hair follicles of induced EGFP-IRES-CreERT2 x Rosa26-LacZ mice after 14 months. $L a c Z$ staining revealed that the numbers of blue follicles had remained essentially unchanged (Fig. 4). Histological analysis revealed thatlike the situation at earlier time points-all cell types of the follicle were represented in the blue clones, corroborating the multipotency of the cells (not shown). These observations implied that the $\operatorname{Lgr} 5^{+\mathrm{ve}}$ cells represent longterm stem cells of the hair follicle.

\section{METHODS}

Mice. LGR5-EGFP-IRES-CreERT2 mice were generated by homologous recombination in embryonic stem cells targeting an EGFP-IRES-CreERT2 cassette to the ATG of LGR5. Rosa26-LacZ Cre reporter mice were obtained from Jackson Labs.

Tamoxifen induction. Mice of $>8$ weeks were injected intraperitoneally with $200 \mu \mathrm{l}$ of tamoxifen in sunflower oil at $10 \mathrm{mg} / \mathrm{ml}$.

BrdU injection. Mice were injected intraperitoneally at 4-hour intervals with $200 \mu \mathrm{l}$ of a BrdU solution in phosphate-buffered saline (PBS) at $5 \mathrm{mg} / \mathrm{ml}$.

Tissue preparation for immunohistochemistry, GFP confocal microscopy, and LacZ analysis. These were performed as described previously (Barker et al. 2007; Jaks et al. 2008).

\section{CONCLUSIONS}

Our previous observations have provided evidence for the existence of a pool of cycling $\operatorname{Lgr} 5^{+\mathrm{ve}}$ stem cells in the epithelium of the small intestine and colon and in hair follicles. Of note, the first two organs are of endodermal origin, whereas the skin derives from ectoderm, implying that Lgr5 represents a stem cell marker across germ layers. The $\operatorname{Lgr} 5^{+\mathrm{ve}}$ cells are generally not quiescent, but they are rapidly cycling, as evidenced by the expression of Ki67 and phosphohistone H3, the incorporation of BrdU, and the observed kinetics of self-renewal (Barker et al. 2007; Jaks et al. 2008). $\operatorname{Lgr}^{+\mathrm{ve}}$ cells of the small intestine appear to be more actively dividing than their colonic counterparts, likely reflecting differences in the rate of epithelial turnover between the two organs. We have not analyzed cell cycle kinetics of the $\operatorname{Lgr} 5^{+\mathrm{ve}}$ cells in the hair

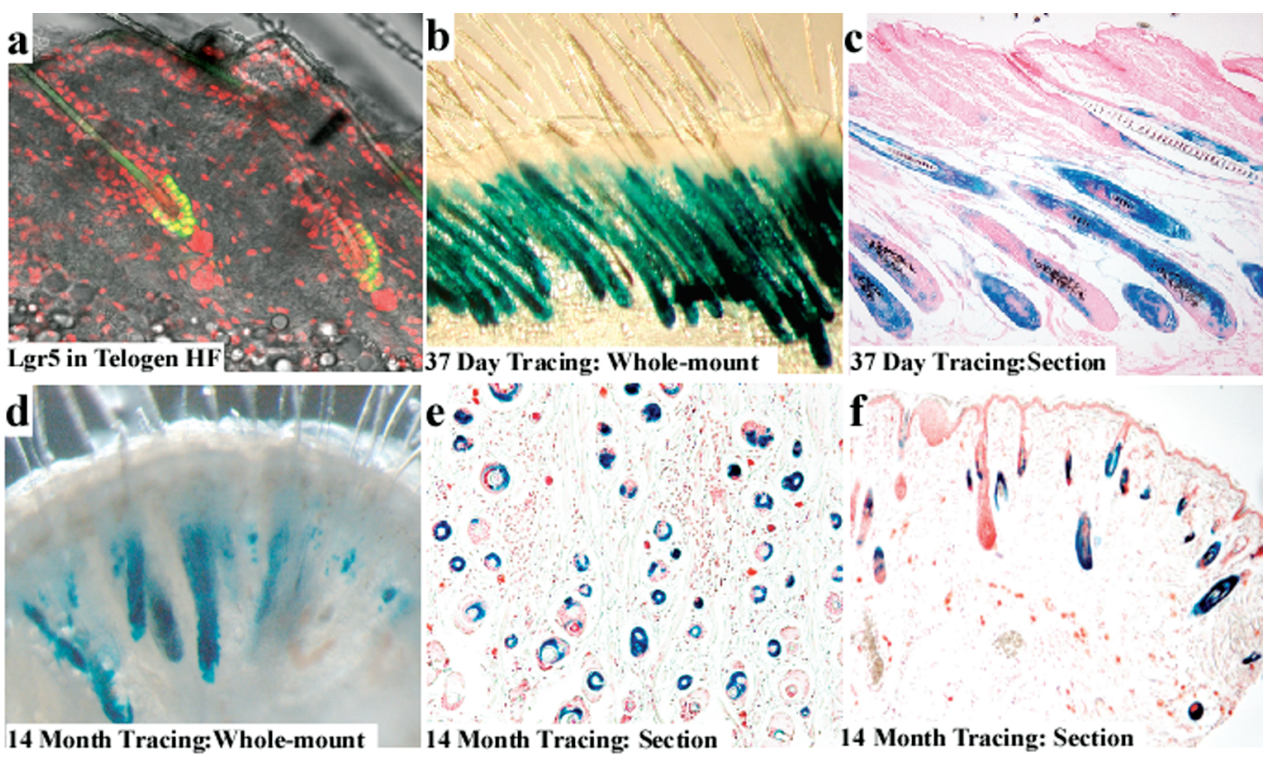

Figure 4. Very long-term lineage tracing in hair follicles. (a) LGR5-EGFP-IRES-CreERT2 knockin mouse. GFP expression in a telogen hair follicle to indicate where tracing starts; $(b)$ entirely labeled hair follicles 37 days after tamoxifen induction; $(c)$ histological analysis of $b ;(d-f)$ the same as in $b$ and $c, 14$ months after tracing. 
follicle. It appears somewhat counterintuitive that stem cells are actively dividing. This is, however, not unprecedented. Germ stem cells in the Drosophila testis and ovary of the fly, arguably the best-studied adult stem cells in animals, cycle throughout the lifetime of the adult fly (Ohlstein et al. 2004). Similarly, a recent elegant study based on a very similar tracing strategy as exploited in the current study, demonstrated that adult stem cells of mammalian skin are continuously cycling (Clayton et al. 2007). The observations in the current study imply that $\operatorname{Lgr} 5^{+\mathrm{ve}}$ cells in the small intestine accomplish the surprising feat of predictedly completing more than 400 cell cycles during the duration of the experiment, without deleterious effects on their telomeres, their genomic content, or their capacity to serve as stem cells to the epithelium. In essence, we believe that the $\operatorname{Lgr} 5^{+\mathrm{v} e}$ cells of the three organs studied here constitute stem cell pools that persist for the lifetime of an animal, given that a mouse rarely lives beyond 1.5-2 years of age. If these observations can be extrapolated to humans, our CBC cells complete an astounding number of cell cycles.

It is rather unusual that adult stem cells can be defined based on the expression of a single gene. This phenomenon may not be restricted to the intestine and hair follicle, because we observe highly restricted $\operatorname{Lgr} 5$ expression in several other tissues. Although patterns of proliferation in stomach glands have indicated that the epithelial stem cells reside at the isthmus, halfway between the gland base and epithelial surface (Bjerknes and Cheng 2002), we find Lgr 5 expressed at gland bottoms. Ongoing lineage-tracing experiments imply that entire glands derive from these cells (N. Barker and $\mathrm{H}$. Clevers, unpubl.). In the mammary gland, stem cells reside in the basal epithelial layer (Sleeman et al. 2007), where we observe Lgr5 expression (not shown). Lgr5 may thus represent a more general marker of adult stem cells. Two closely related genes exist in the mammalian genomes, Lgr4 and Lgr6. Our ongoing studies using similar knockin strategies indicate that these two homologs are expressed in unique, yet overlapping, expression patterns when compared to Lgr5. At several sites, we believe that the two homologs mark stem cells, much like Lgr5 (A. Haegebarth et al., unpubl.). The function of the three Lgr genes in stem cells remains to be determined, but it is likely redundant among the three homologs.

\section{REFERENCES}

Alonso, L. and Fuchs, E. 2006. The hair cycle. J. Cell Sci. 119: 391-393.

Blanpain, C., Lowry, W.E., Geoghegan, A., Polak, L., and Fuchs, E. 2004. Self-renewal, multipotency, and the existence of two cell populations within an epithelial stem cell niche. Cell 118: 635-648.

Barker, N., van Es, J.H., Kuipers, J., Kujala, P., van den Born, M., Cozijnsen, M., Haegebarth, A., Korving, J., Begthel, H., Peters, P.J., et al. 2007. Identification of stem cells in small intestine and colon by the marker gene Lgr5. Nature 449: 1003-1007.

Bjerknes, M. and Cheng, H. 1981. The stem-cell zone of the small intestinal epithelium. III. Evidence from columnar, enteroendocrine, and mucous cells in the adult mouse. Am. J. Anat. 160: 77-91.

Bjerknes, M. and Cheng, H. 1999. Clonal analysis of mouse intestinal epithelial progenitors. Gastroenterology 116: 7-14. Bjerknes, M. and Cheng, H. 2002. Multipotential stem cells in adult mouse gastric epithelium. Am. J. Physiol. Gastrointest. Liver Physiol. 283: G767-G777.

Braun, K.M., Niemann, C., Jensen, U.B., Sundberg, J.P., SilvaVargas, V., and Watt, F.M. 2003. Manipulation of stem cell proliferation and lineage commitment: Visualisation of labelretaining cells in wholemounts of mouse epidermis. Development 130: 5241-5255.

Cheng, H. and Leblond, C.P. 1974. Origin, differentiation and renewal of the four main epithelial cell types in the mouse small intestine. V. Unitarian Theory of the origin of the four epithelial cell types. Am. J. Anat. 141: 537-561.

Clayton, E., Doupé, D.P., Klein, A.M., Winton, D.J., Simons, B.D., and Jones, P.H. 2007. A single type of progenitor cell maintains normal epidermis. Nature 446: 185-189.

Cotsarelis, G., Sun, T.T., and Lavker, R.M. 1990. Label-retaining cells reside in the bulge area of pilosebaceous unit: Implications for follicular stem cells, hair cycle, and skin carcinogenesis. Cell 61: 1329-1337.

Gregorieff, A. and Clevers, H. 2005. Wnt signaling in the intestinal epithelium: From endoderm to cancer. Genes Dev. 19: 877-890.

Hsu, S.Y., Liang, S.G., and Hsueh, A.J. 1998. Characterization of two LGR genes homologous to gonadotropin and thyrotropin receptors with extracellular leucine-rich repeats and a G protein-coupled, seven-transmembrane region. Mol. Endocrinol. 12: 1830-1845.

Ito, M., Kizawa, K., Hamada, K., and Cotsarelis, G. 2004. Hair follicle stem cells in the lower bulge form the secondary germ, a biochemically distinct but functionally equivalent progenitor cell population, at the termination of catagen. Differentiation 72: 548-557.

Jaks, V., Barker, N., Kasper, N., van Es, J.H., Snippert, H., Clevers, H., and Toftgård, R. 2008. Lgr5 marks cycling, yet long-lived, hair follicle stem cells. Nature (in press).

Korinek, V., Barker, N., Moerer, P., van Donselaar, E., Huls, G., Peters, P.J., and Clevers, H. 1998. Depletion of epithelial stem-cell compartments in the small intestine of mice lacking Tcf-4. Nat. Genet. 19: 379-383.

Morris, R.J., Liu, Y., Marles, L., Yang, Z., Trempus, C., Li, S., Lin, J.S., Sawicki, J.A., and Cotsarelis, G. 2004. Capturing and profiling adult hair follicle stem cells. Nat. Biotechnol. 22: 411-417.

Nijhof, J.G., Braun, K.M., Giangreco, A., van Pelt, C., Kawamoto, H., Boyd, R.L., Willemze, R., Mullenders, L.H., Watt, F.M., de Gruijl, F.R., et al. 2006. The cell-surface marker MTS24 identifies a novel population of follicular keratinocytes with characteristics of progenitor cells. Development 133: 3027-3037.

Ohlstein, B., Kai, T., Decotto, E., and Spradling, A. 2004. The stem cell niche: Theme and variations. Curr. Opin. Cell Biol. 16: 693-699.

Oshima, H., Rochat, A., Kedzia, C., Kobayashi, K., and Barrandon, Y. 2001. Morphogenesis and renewal of hair follicles from adult multipotent stem cells. Cell 104: 233-245.

Sleeman, K.E., Kendrick, H., Robertson, D., Isacke, C.M., Ashworth, A., and Smalley, M.J. 2007. Dissociation of estrogen receptor expression and in vivo stem cell activity in the mammary gland. J. Cell Biol. 176: 19-26.

Soriano, P. 1999. Generalized lacZ expression with the ROSA26 Cre reporter strain. Nat. Genet. 21: 70-71.

Stappenbeck, T.S., Mills, J.C., and Gordon, J.I. 2003. Molecular features of adult mouse small intestinal epithelial progenitors. Proc. Natl. Acad. Sci. 100: 1004-1009.

Trempus, C.S., Morris, R.J., Bortner, C.D., Cotsarelis, G., Faircloth, R.S., Reece, J.M., and Tennant, R.W. 2003. Enrichment for living murine keratinocytes from the hair follicle bulge with the cell surface marker CD34. J. Invest. Dermatol. 120: 501-511.

Tumbar, T., Guasch, G., Greco, V., Blanpain, C., Lowry, W.E., Rendl, M., and Fuchs, E. 2004. Defining the epithelial stem cell niche in skin. Science 303: 359-363.

van der Flier, L.G., Sabates-Bellver, J., Oving, I., Haegebarth, A., 
De Palo, M., Anti, M., van Gijn, M.E., Suijkerbuijk, S., van de Wetering, M., Marra, G., et al. 2007. The intestinal Wnt/TCF signature. Gastroenterology 132: 628-632.

van de Wetering, M., Sancho, E., Verweij, C., de Lau, W., Oving, I., Hurlstone, A., van der Horn, K., Batlle, E.,
Coudreuse, D., Haramis, A.P., et al. 2002. The $\beta$-catenin/ TCF-4 complex imposes a crypt progenitor phenotype on colorectal cancer cells. Cell 111: 241-250.

Winton, D.J. and Ponder, B.A. 1990. Stem-cell organization in mouse small intestine. Proc. Biol. Sci. 241: 13-18. 


\section{$\overbrace{\text { CSH\& }}^{\infty}$ Cold Spring Harbor Symposia SYMPOSIA}

\section{Very Long-term Self-renewal of Small Intestine, Colon, and Hair Follicles from Cycling Lgr5 ${ }^{+\mathrm{Ve}}$ Stem Cells}

N. Barker, J.H. van Es, V. Jaks, et al.

Cold Spring Harb Symp Quant Biol 2008 73: 351-356 originally published online November 6, 2008 Access the most recent version at doi:10.1101/sqb.2008.72.003

References This article cites 26 articles, 7 of which can be accessed free at: http://symposium.cshlp.org/content/73/351.full.html\#ref-list-1

License

Email Alerting Receive free email alerts when new articles cite this article - sign up in the Service box at the top right corner of the article or click here.

To subscribe to Cold Spring Harbor Symposia on Quantitative Biology go to: http://symposium.cshlp.org/subscriptions 